\title{
Prevalence of Risk Factors for Cardiovascular Diseases among Selected Military Personnel of Bangladesh
}

Rustom ATMA 1 , Rahman $\mathrm{MM}^{2}$, Iqbal SA ${ }^{3}$, Hasan MNA ${ }^{4}$

DOI: https://doi.org/10.3329/jafmc.v14i2.45906

\begin{abstract}
Introduction: Incidence of cardiovascular diseases (CVDs) in Bangladesh has been increasing as seen by various studies conducted across the country. Reliable data regarding modifiable risk factors of CVDs like body mass index (BMI), blood pressure (BP) and cholesterol levels are not available pertaining to military personnel.
\end{abstract}

Objectives: To assess the prevalence of risk factors for CVDs among adult military personnel of a selected unit of the Bangladesh Army.

Materials and Methods: This cross-sectional descriptive study was carried out among 835 adult participants from July 2018 to December 2018 in a military unit of Bangladesh Army. BP, BMI, fasting blood total cholesterol and sugar was assessed as per the standard procedure. Information regarding socio-demographic characteristics was collected using a pretested questionnaire. New American College of Cardiology guidelines-2017 used for categorization of hypertension and WHO criteria were used for grading obesity. Fasting blood sugar levels $\geq 126 \mathrm{mg} / \mathrm{dl}$ and total cholesterol> $200 \mathrm{mg} / \mathrm{dl}$ considered as increased.

Results: Among the study population, $91 \%$ were non-smoker, $82 \%$ were married but stayed away from family and $85.3 \%$ were taking more fatty food. Only $6.2 \%$ of participants have given the history of taking extra salt. Prevalence of obesity raised serum cholesterol, and raised blood sugar were $0.4 \%, 0.6 \%$ and $0.6 \%$ respectively. Prevalence of pre-obese was $15.2 \%$ and stage- 1 hypertensionwas $39.2 \%$ among $30-44$ years' age group.

Conclusion: The high prevalence of stage-1 hypertension and its association with overweight in this young, physically active military population indicates an urgent need for targeted interventions to reduce the cardiovascular risk for a healthy life.

Key-words: Risk Factors, Cardiovascular Diseases, Military Personnel.

\section{Introduction}

The cardiovascular diseases (CVDs) is rising in developing countries, particularly low and middle-income countries (LMICs), creating a major challenge for the health sector.
According to the World Health Organization (WHO), CVDs were the causes of 17.5 million deaths (31\% of all death) around the world in 2012, of which $80 \%$ occurred in LMICs ${ }^{1}$ and $85 \%$ of all global disability ${ }^{2}$. CVDs and its associated known risk factors account for $13.4 \%$ of disability-adjusted life years (DALYs) lost in Bangladesh ${ }^{3}$. The major CVDs risk factors such as abnormal glucose metabolism, high blood pressure, dyslipidemia along with increasing age are well established ${ }^{2,4}$. Other behavioural risk factors like unhealthy diet (rich in salt, fat and sugars), physical inactivity, harmful use of alcohol and tobacco, raised body mass index, waist-hip ratio are well-known causes of CVDs ${ }^{4}$.

Obesity constitutes a major risk for CVDs both directly (through underlying insulin resistance and inflammatory changes) and indirectly through the effect on other immediate risk factors like type 2 Diabetes Mellitus (T2DM), dyslipidemia and hypertension (HTN). After China and India, Bangladesh ${ }^{5}$ has the highest prevalence of diabetes mellitus (DM) among LMICs (8.4 million or $10 \%$ of the population) and the prevalence could increase by $13 \%$ by 2030 . According to the INTER-HEART study, Bangladeshi people had the highest prevalence of CVD risk factors among five South-Asian countries with the prevalence of self-reported history of hypertension (14.3\%), abdominal obesity $(43.3 \%)$, current and former smoking $(59.9 \%)$ and the lowest prevalence for regular physical activity $(1.3 \%)$ and daily intake of fruits and vegetables $(8.6 \%)^{6}$. Rapid economic development and increasing westernized lifestyle of the past few decades has led to increased prevalence of these diseases and has escalated in alarming proportions among Bangladeshi in recent years ${ }^{7}$.

In Bangladesh, 99.6\% male and 97.9\% females are exposed to at least one of the established risks of CVDs at a younger age $^{3,8,9}$. The military personnel lead a healthy lifestyle which includes regular physical exercise, good nutrition and easy access to preventive healthcare and are thus expected to be healthier than the native population. However, military service is also inherently associated with long hours of work, strong disciplinary mechanisms, stress of separation from family, uncongenial climatic and terrain conditions and the impending fear of enemy action leading to increased risk of CVDs. Considering the increasing trend of CVDs related

1. Lt Col ATMA Rustom, MBBS, MPH, Instructor of Medicine, Armed Forces Medical Institute, Dhaka (E-mail: atmarustom@gmail. com) 2. Maj Gen Md Mahbubur Rahman, MBBS, MMEd, MCPS, DPH,Director General, Directorate General of Drug Administration, Ministry of Health \& Family Welfare,Bangladesh3. Brig Gen Syed Asif Iqbal, MBBS, FCPS (Med), Chief Physician General, CMH Dhaka 4. Maj Mohammad Nazmul Amin Hasan, MBBS, Graded Specialist in Medicine, BANRDB-2, MONUSCO C/O 38 E. Bengal, Jalalabad Cantonment, Sylhet. 
mortality in Bangladesh, there is aneed to understand the epidemiology of CVDs and its risk factors in army lifestyle. According to new American College of Cardiology (ACC) and American Heart Association (AHA) guidelines-2017 for the detection, prevention, management and treatment of high $\mathrm{BP}$, it should be treated earlier with lifestyle changes and in some patients with medication ${ }^{10}$ at $130 / 80 \mathrm{mmHg}$ rather than $140 / 90$ $\mathrm{mmHg}$. This cross-sectional study was conducted with an aim to assess the prevalence of major metabolic cardiovascular disease risk factors, overall epidemiology and their correlates amongst the troops of Bangladesh Army.

\section{Materials and Methods}

This cross-sectional observational study was conducted among adult military personnel during the period of July 2018 to December 2018. Total 835 apparently healthy adult personnel between the age of 18-48 years irrespective of sex from a military unit of Bangladesh were included in this study. Participants having known case of ischemic heart disease and who were not available during the study period or refused to get examined were excluded from the study. All subjects currently on anti-hypertensive or hypoglycaemic medications or having written prescriptions of anti-hypertensive or hypoglycaemic drugs were classified as hypertensive or diabetic irrespective of their current BP or blood sugar reading.Written informed consent was obtained from all the participants. Data regarding socio-demographic characteristics, health-related information and anthropometric profile was collected by trained healthcare workers using pre-tested questionnaire.

The study participants were educated regarding the importance of a fasting blood sample prior to the day ofsample collection. Calibration of all the instruments used in the study was carried out prior to the commencement of the study. Body weight to nearest $0.5 \mathrm{~kg}$ and height to nearest $0.5 \mathrm{~cm}$ was measured using standardized techniques with an automated balance and a wallmounted stadiometer. The blood samples were collected in the laboratories of a Combined Military Hospital (CMH), Jalalabad maintaining all precautions. Fasting blood cholesterol levels were determined using a semi-auto analyzer. BMI was calculated as Quetelet's index [Weight in $\mathrm{Kg} /($ Heightin $\mathrm{m}) 2]$. BP was measured by trained personnel. Hypertension was categorized as Elevated BP (systolic 120-129 and diastolic <80 mm Hg), Stage 1 Hypertension (systolic 130-139 or diastolic $80-89 \mathrm{~mm} \mathrm{Hg}$ ) and Stage 2 Hypertension (systolic $\geq 140$ or diastolic $\geq 90 \mathrm{~mm} \mathrm{Hg}$ ) as per ACC guidelines-2017. Pre-obese/overweight (BMI 25-29.9 Kg/ $\mathrm{m} 2$ ), and Raised cholesterol (>200 mg/dL) level was categorized as per WHO criteria. The study protocol was approved by the institutional ethics committee before starting the study.

\section{Results}

Among 835 study participants, $811(97.13 \%)$ male and $24(2.87 \%)$ female with a mean age of 32 years and a majority $70.4 \%$ belonged tothe age group 30-44 years. Among the participants about $91 \%$ were non-smoker and $82 \%$ were married but stayed away from family. Most of the participants $83.8 \%$ had monthly income between 30,000-50,000 taka. Only 1.8\% participants did not practice regular physical exercise (Table-I). A large proportion of the study participants $327(39.2 \%)$ were suffering from elevated BP. While 224(26.8\%) were suffering from stage-1 hypertension and 224(26.8\%) from stage-2 hypertension. Prevalence of overweight or pre-obesity among participants was found to be low which were only $127(15.2 \%)$ and only $0.4 \%$ was obese. Regarding serum cholesterol only $5(0.6 \%)$ of the study participants have high cholesterol (>200mg/dL) level and amongst them $3(0.4 \%)$ participants had borderline high and $2(0.2 \%)$ had high (Table-II). Prevalence of overweight was high $(93 ; 11.1 \%$ ) among $30-44$ years than the other age group. The risk factor was also found to be high among married but stayed away from family (13.8\%) than the married participants who stayed with their family (Table-III). Elevated BP was more $(26.71 \%)$ among $30-44$ years of age group than others. Prevalence of Elevated blood pressure among married but stayed away from family was also significantly higher $(35.09 \%)$ than who stayed with family (Table-IV).

Table-l: Socio-demographic characteristics of the study participants $(n=835)$

\begin{tabular}{|l|l|r|r|}
\hline \multicolumn{2}{|l|}{ Characteristics } & Number & Percentage \\
\hline \multirow{3}{*}{ Age in years } & $18-29$ & 219 & 26.2 \\
\cline { 2 - 4 } & $30-44$ & 588 & 70.4 \\
\cline { 2 - 4 } & $\geq 45$ & 28 & 3.4 \\
\hline \multirow{3}{*}{ Sex } & Male & 811 & 97.13 \\
\cline { 2 - 4 } & Female & 24 & 2.87 \\
\hline \multirow{3}{*}{ Physital status } & Unmarried & 77 & 9.2 \\
\cline { 2 - 4 } & Married but stayed away from family & 683 & 81.8 \\
\cline { 2 - 4 } & Married but stayed with family & 75 & 9.0 \\
\hline \multirow{2}{*}{ Smoking Habit } & No exercise & 15 & 1.8 \\
\cline { 2 - 4 } & Moderate exercise & 820 & 98.2 \\
\cline { 2 - 4 } & Non-Smoker & 761 & 91.2 \\
\cline { 2 - 4 } & Smoker (1- $\geq 20$ sticks/day) & 74 & 8.8 \\
\hline
\end{tabular}

Table-II: Prevalence of hypertension, obesity and serum cholesterolamong the study participants $(n=835)$

\begin{tabular}{|l|l|r|c|}
\hline \multicolumn{2}{|c|}{ Characteristics } & Number & Percentage \\
\hline \multirow{3}{*}{ Hypertension } & Elevated BP & 327 & 39.2 \\
\cline { 2 - 4 } & Stage-1 Hypertension & 224 & 26.8 \\
\cline { 2 - 4 } & Stage-2 Hypertension & 224 & 26.8 \\
\hline \multirow{2}{*}{ Obesity } & Overweight (Pre-obese) & 127 & 15.2 \\
\cline { 2 - 4 } & Obese & 03 & 0.4 \\
\hline \multirow{3}{*}{ Serum Total Cholesterol } & Normal & 830 & 99.4 \\
\cline { 2 - 4 } & Borderline & 03 & 0.4 \\
\cline { 2 - 4 } & High & 02 & 0.2 \\
\hline
\end{tabular}

Table-III: Prevalence of overweight in relation to age and marital status $(n=835)$

\begin{tabular}{|c|c|c|c|}
\hline \multirow{2}{*}{\multicolumn{2}{|c|}{ Category }} & \multicolumn{2}{|c|}{ Overweight } \\
\hline & & \multirow{2}{*}{$\begin{array}{c}\text { Number } \\
21 \\
\end{array}$} & \multirow{2}{*}{$\frac{\text { Percentage }}{2.5}$} \\
\hline \multirow{3}{*}{ Age in years } & $18-29$ & & \\
\hline & $30-44$ & 93 & 11.1 \\
\hline & $\geq 45$ & 13 & 1.6 \\
\hline \multirow{2}{*}{ Married Participants } & Stayed away from family & 115 & 13.8 \\
\hline & Stayed with family & 12 & 1.4 \\
\hline
\end{tabular}


Table-IV: Prevalence of elevated BP in relation to age and marital status $(n=835)$

\begin{tabular}{|l|l|r|c|}
\hline \multirow{2}{*}{ Category } & \multicolumn{2}{c|}{ Elevated Blood Pressure } \\
\cline { 3 - 4 } & & Number & Percentage \\
\hline \multirow{3}{*}{ Age in years } & $18-29$ & 92 & 11.02 \\
\cline { 2 - 4 } & $30-44$ & 223 & 26.71 \\
\cline { 2 - 4 } & $\geq 45$ & 12 & 1.44 \\
\hline Married & Stayed with family & 34 & 4.07 \\
\cline { 2 - 4 } Participants & Stayed away from family & 293 & 35.09 \\
\hline
\end{tabular}

\section{Discussion}

This study revealed a lower prevalence of risk factors of CVDs among adult personnel of Bangladesh army. The prevalence of obesity wasmuch lower than World Health Statistics forBangladesh as revealed by WHO in 2016(0.4\% vs $3.0 \%)^{11}$. But the prevalence of elevated BP and Stage 1 Hypertension was quitehigh $(39.2 \%$ and 26.8 vs $21.0 \%$ respectively) in comparison to World Health Statistics for Bangladesh ${ }^{11}$. Wide variations from WHO data and present study can probably be explained on the basis of regular physical activity and healthy lifestyle followed by military personnel| ${ }^{12-14}$. The various peoplehave a different prevalence of CVD risk factors due to genetic, socioculturalland dietary habits ${ }^{15}$. As armed forces comprise of aheterogeneous group of persons from across the country so it might be considered as more reliable data. However, nationwide statistics available from Biswas $T$ et $\mathrm{al}^{16}$ in Bangladesh reveal a lower prevalence of obesity $(0.4 \%$ vs $3.0 \%)$. In contrary, Fatema $\mathrm{K}$ et $\mathrm{al}^{17}$ revealshigher prevalence of elevated BP (39.2\% vs $15.1 \%)$.

Prevalence of high cholesterol level was much lower $(0.6 \%$ vs $1.3 \%$ ) than estimates available from a national study by Zaman MM et $\mathrm{al}^{7}$ in 2016. The differences can be attributed as the younger age group studied the smaller sample size and no separate male and female data availability. Indian army personnel data from the southern part of the nation revealed high prevalence of CVD risk factors like smoking (17.9\%), pre-obesity (29.9\%) and pre-hypertension (79.9\%)18. This study indicates low prevalence of pre-obese (15.2\%), elevatedBP, stage 1 and stage 2 hypertension (39.2\%, 26.8\% and $26.8 \%$ respectively) among military personnel except smoking (8.8\%) compared to study conducted among Indian $a^{a r m y}{ }^{18}$. The reason for higher prevalence with respect to preobesity and different category of hypertension compared to the present study might have occurred as different age groups have been studied in both research works. Study conducted by Varma et $\mathrm{al}^{19}$ among healthy army personnel in India revealed a higher proportion of hypercholesterolemia and lower levels of pre-hypertension and hypertension compared to the present study. CVDs are both a life-course and lifestyle disease. Approximately one-third of individuals serving in the armed forces are in age group (>30 years) with higher risk of developing CVDs and a large proportion of this study participants in the same age group were found suffering from pre-obese, elevated BP and stage-1 hypertensive state.

The high burden of pre-obese state among healthy military personnel highlights that ideal weight for age criteria used in armed forces requires a relook as per BMl standards suggested for Asians for defining obesity. The large proportion of pre-obese individuals if not detected early would present a formidable challenge tothe military healthcare system coupled with an enormous burden of hypertension. Though the existing system of healthy lifestyle in army is in place, the considerable burden of CVD risk factors as evident from this study points towards priority-based public health approach. Majority of these diseases remain hidden and not detected until a catastrophic event like acute coronary syndrome, stroke etc. occur. Instead of opportunistic screening, the enormous burden of CVD risk warrants regular public health surveillance of CVD risk factors.

\section{Conclusion}

The lower levels of established CVD risk factors in this study implythe success of primary prevention activities. However, conditions like pre-obesity, quite high level of elevated BP and stage-1 hypertension among military personnel requires an insight into the standards followed for medical examination in view of revised guidelines for obesity and hypertension to nip the evil in the bud. Further,multi-centric studies can be conducted to frame the guidelines for obtaining these standards.

\section{References}

1. World Health Organization. CVDs.Fact Sheet N 317. Availableat http://wwwwhoint/mediacentre/factsheets/fs317/en/indexhtml.

2. Hussain SM, Oldenburg B, Wang $Y$ et al. Assessment of cardiovascular disease risk in South Asian populations. Int J Vasc Med 2013; 2013:786-801.

3. El-Saharty S, Ahsan KZ, Koehlmoos TL et al. Tackling Noncommunicable diseases in Bangladesh: Now is the Time. Direction in development. Washington DC:World BankLicense: Creative Commons Attribution CCBY 3.0. World Bank Publications; 2013:1-13.

4. Kannel WB, McGee D. Diabetes and glucose tolerance as risk factors for cardiovascular disease: The Framingham study. Diabetes Care 1979; 2(2):120-6.

5. Whiting DR, Guariguata L, Weil $C$ et al. IDF diabetes atlas: Global estimates of the prevalenceof diabetes for 2011 and 2030. Diabetes Res Clin Pract 2011; 94(3):311-21.

6. Joshi P, Islam S, Pais $P$ et al. Risk factors for early myocardial infarction in South Asians compared with individuals in other countries. JAMA 2007; 297(3):286-94. 
7. Zaman MM, Choudhury SR, Ahmed J et al. Blood glucose and cholesterol levels in adult population of Bangladesh: Results from STEPS 2006 survey. Indian Heart Journal 2016; 68:52-6.

8. Islam SR-u, Rahman F, Siddiqui MMR. Bangladesh is Experiencing Double Burden with Infectiousdiseases and Non-communicable Diseases (NCD's): An Issue of Emerging Epidemics. Anwer Khan Modern Medical College Journal 2014; 5(1):46-50.

9. Enas E, Garg A, Davidson M et al. Coronary heart disease and its risk factors in first-generation immigrant Asian Indians to the United States of America. Indian Heart J 1995; 48(4):343-53.

10. Whelton PK et al. 2017 ACC/AHA/AAPA/ABC/ACPM/AGS/APhA/ ASH/ASPC/NMA/PCNA Guideline for the Prevention, Detection, Evaluation, and Management of High Blood Pressure in Adults. ACC. org/GMSHBP.Citation: J Am Coll Cardiol 2017:1-283.

11. WHO expert consultation. Appropriate body-mass index for Asian populations and its implications for policy and intervention strategies. Lancet 2004; 363:157-63.

12. World Health Organization. Prevention and Control of NonCommunicable Diseases: Guidelines for primary healthcare in low resource settings, 2012.
13. National Cholesterol Education Program. National heart, lung, and blood institute National Institutes of Health; NIH Publication No. 02-5215. September 2002.

14. World Health Organization. CVDs Fact Sheet for Bangladesh. NCD country profile, 2018.Available from: http://www.who.int/nmh/ countries/bgd_en.pdf.

15. Kumar P, Mallik D, Mukhopadhyay DK et al. Prevalence of diabetes mellitus, impaired fasting glucose, impaired glucose tolerance, and its correlates among police personnel in Bankura District of West Bengal. Indian J Public Health 2013; 57(1):24-8.

16. Biswas T, Garnett SP, Pervin $S$ et al. The prevalence of underweight, overweight and obesity in Bangladeshi adults: Data from a national survey. PLoS One 2001; 12(5):e0177395.

17. Fatema K, Zwar NA, Milton A et al. Prevalence of risk factors for cardiovascular diseases in Bangladesh: A Systematic Review and Meta-Analysis. PLoS One 11(8): e0160180.

18. Ray S, Kulkarni B, Sreenivas A. Prevalence of prehypertension in young military adults and its association with overweight and dyslipidaemia. Indian J Med Res 2011; 134:162-7.

19. Varma PP, Raman DK, Ramakrishnan TS et al. Prevalence of early stages of chronic kidney disease in healthy army personnel. MJAFI 2011; 67(1):9-11. 